\title{
UNIDADE DIDÁTICA E PLANO DE ATIVIDADES: UMA PRÁTICA DE RESISTÊNCIA PEDAGÓGICA PARA O DESENVOLVIMENTO DE SENTIDOS EM LIBRAS E EM LÍNGUA PORTUGUESA
}

\section{TEACHING UNIT AND ACTIVITY PLAN: A PEDAGOGICAL RESISTANCE PRACTICE FOR THE DEVELOPMENT OF SENSES IN LIBRAS AND PORTUGUESE LANGUAGE}

\author{
Fernanda Beatriz Caricari de Morais \\ Instituto Nacional de Educacao de Surdos, INES, Rio de Janeiro, RJ, Brasil \\ Osilene Maria de Sá e Cruz \\ Instituto Nacional de Educacao de Surdos, INES, Rio de Janeiro, RJ, Brasil
}

Resumo: A busca por materiais didáticos que contemplem as necessidades de aprendizes surdos tem sido cada vez mais frequente entre profissionais que atuam em ambientes escolares regulares/inclusivos e em escolas bilíngues que adotam o uso da Língua Brasileira de Sinais e da Língua Portuguesa escrita como línguas de instrução. Com base em pesquisadores preocupados com essa temática (FERNANDES, 2002; PEREIRA, 2014; LODI, 2013; MORAIS, 2013; MORAIS; CRUZ, 2016; 2017; entre outros), objetivamos discutir questóes sobre o ensino de habilidades de compreensão e produção escrita para alunos surdos, aprendizes de Língua Portuguesa como segunda língua. Além disso, refletimos sobre o ensino de línguas com base em tarefas com enfoque comunicativo (MORAIS; CRUZ, 2016; 2017), realizado por meio de gêneros textuais e textos autênticos, publicados na mídia impressa e eletrônica (RAMOS, 2004). Para isso, a partir das nossas experiências acadêmicas, é apresentado um instrumento de trabalho (Plano de Atividades e Unidade Didática), que visa auxiliar professores em formação inicial e professores que já atuam com aprendizes surdos na Educação Básica.

Palavras-chave: Língua Portuguesa como Segunda Língua para Surdos; Material Didático para Surdos; Conceito de Tarefa; Abordagem Comunicativa.

Abstract: The search for teaching materials that contemplate the needs of deaf learners has been increasingly frequent among professionals working in regular/inclusive school and in bilingual schools that adopt the use of the Brazilian Sign Language and the written Portuguese. Based on researchers concerned with this subject (FERNANDES, 2002; PEREIRA, 2014; LODI, 2013; MORAIS; CRUZ, 2016; 2017; and others), this article aims to discuss questions about the teaching of comprehension skills and written production for deaf students, learners of Portuguese as a second language. In addition, the paper seeks to reflect on the teaching 
of languages based on tasks with communicative focus (MORAIS; CRUZ, 2016; 2017), carried out through textual genres and authentic texts, published in print and electronic media (RAMOS, 2004). To this end, from the academic and professional experiences of the researchers, a working tool (Didactic Unit and Activity Plan) is presented, which aims to assist teachers in training and teachers who work with deaf learners in Basic Education.

Keywords: Portuguese as a Second Language for Deaf Students; Didactic Material for Deaf Students; Concept of task; Communicative Approach.

\section{Introduçáo}

Avanços na educação de surdos têm sido evidentes nas últimas décadas, decorrentes de algumas açôes políticas, como o reconhecimento da Língua Brasileira de Sinais - LIBRAS (Lei no 10.436/2002) e sua regulamentaçáo (Decreto no 5.626/2005), estabelecendo, entre outras açôes, a formaçáo de profissionais para a educaçáo de surdos, por meio de cursos de Licenciatura (Letras/Libras, Letras/Libras/Ensino de Língua Portuguesa para surdos, Pedagogia para a formação do profissional bilíngue [Libras/ Língua Portuguesa]) e de cursos ou agências voltados para a formação de profissionais Tradutores Intérpretes de Libras e Língua Portuguesa (TILSP).

Somam-se a essas conquistas outros documentos legais que também apontam para a melhoria na qualidade de ensino para esses aprendizes, como a Declaração de Salamanca (UNESCO, 1994), a Lei no 12.319 (BRASIL, 2010) que regulamenta o exercício da profissão de Tradutor e Intérprete da Língua Brasileira de Sinais - LIBRAS.- e a Lei Brasileira de Inclusão no 13.146/2015 (BRASIL, 2015), que prevê o ensino adequado, que promova a efetiva inclusão escolar e náo a exclusão dos alunos, independentemente da sua necessidade. Entretanto, a realidade mostra que a existência de amparos legais não tem sido suficiente para a solução dos problemas enfrentados por professores e gestores, que demonstram dificuldades para trabalhar o ensino de forma eficaz, fazendo com que os alunos sejam vítimas de um sistema de ensino antiquado e destituído de informaçóes sobre estratégias e procedimentos voltados para uma educação de qualidade.

Embora o Decreto no 5.626/2005 se concentre em vários capítulos (II a VI) sobre a formação do professor de Libras e Língua Portuguesa e sobre o direito do aluno ao ensino em uma perspectiva bilíngue (Libras e Língua Portuguesa), e, ainda que o prazo para sua execuçáo tenha sido de até dez anos a partir da sua promulgação, o que encerraria em 2015, a realidade atual mostra que pouco se percorreu nessa jornada e que os desafios continuam sendo muitos. Os professores, mesmo os licenciados 
em Letras-Libras, Letras/Libras-Ensino de Língua Portuguesa para surdos e Pedagogia com enfoque na educação bilíngue, sentem-se limitados em sua formação para o desempenho com total êxito de suas atividades, causando a continuidade no déficit de rendimento educacional e de aprendizagem do aluno surdo. Uma das principais causas desse desalinho está relacionada a estratégias de ensino utilizadas pelo docente para trabalhar habilidades de leitura e escrita com o aprendiz surdo.

Vale destacar que se pode ter um processo de ensino-aprendizagem mais complicado se ainda náo houver uma constituiçáo mais sólida de língua (QUADROS; SCHMIEDT, 2006), pois a aquisição e o domínio da Libras, primeira língua surdo (L1), são primordiais para o letramento do discente. Consequentemente, um aluno que lê e interpreta textos em sua L1 encontra-se mais predisposto para compreender e executar as mesmas tarefas na L2 (Língua Portuguesa escrita).

Com base nessa contextualização, na nossa experiência profissional, no Instituto Nacional de Educação de Surdos - INES, no ensino de Língua Portuguesa escrita para alunos surdos, e nas pesquisas realizadas no grupo de pesquisa Ensino de Lingua Portuguesa para surdos: experiências, desafios e perspectivas ${ }^{1}$, apresentamos, neste artigo, duas ferramentas, Plano de Atividades (PA) e Unidade Didática (UD), que vêm sendo utilizadas com frequência em nossas aulas no curso de Licenciatura em Pedagogia (modalidade bilíngue) do INES, em cursos de extensão e nos cursos de pósgraduação lato sensu "Educação de Surdos: uma perspectiva bilíngue em construção" e "Língua Portuguesa: leitura e escrita no ensino de surdos".

Partimos de uma reflexão teórico-metodológica baseada em estudos sobre gêneros discursivos e metodologias de ensino de leitura e escrita de língua estrangeira (RAMOS, 2004; ELLIS, 2003; SWALES, 1990) e de pesquisas sobre o ensino de Língua Portuguesa como segunda língua para surdos (LP como L2), pautadas em uma perspectiva bilíngue de ensino (FERNANDES, 2002; PEREIRA, 2014; LODI, 2013; MORAIS; CRUZ, 2016; 2017, entre outros) para a elaboração das ferramentas citadas, com o intuito de promover um ensino reflexivo aos alunos, buscando atender suas necessidades e anseios.

Dessa maneira, podemos caracterizar esta pesquisa como uma pesquisa-ação, pois é uma tentativa continuada, sistemática e empiricamente fundamentada em aprimorar a prática (TRIPP, 2005), sendo muito

${ }^{1}$ Grupo cadastrado no CNPq, disponível em: dgp.cnpq.br/dgp/ espelhogrupo/4958669658821338 
utilizada em pesquisas educacionais, por fornecer condiçóes de produzir conhecimentos de uso mais prático, especialmente, no nível pedagógico, promovendo condiçôes para açôes e transformaçóes de situaçóes dentro do próprio ambiente de ensino (THIOLLENT, 2002, p. 75).

A proposta de ensino apresentada neste artigo é utilizada nos materiais didáticos de Língua Portuguesa nos contextos presencial e on-line do curso de Pedagogia do Instituto Nacional de Educação de Surdos, sendo também aplicado em outros contextos (Educação Básica) pelos nossos orientandos da graduação e pós-graduação (Stricto e Latu Sensu).

A pesquisa-ação é a metodologia mais adequada para o que pretendemos por lançar luzes sobre a pesquisa educativa e a prática docente, buscando ampliar as capacidades de compreensão dos professores e suas práticas, favorecendo, assim, mudanças (ELLIOTT, 1997, p. 15).

Nossa realidade mostra que o plano de aula e o livro tradicional, material produzido para alunos ouvintes que aprenderáo o português escrito como sua primeira língua, não contemplam as necessidades de rotina didática do professor de aprendizes surdos. Notamos a dificuldade do profissional em trabalhar o currículo escolar de forma fechada e estanque, pois o público-alvo é constituído por alunos que, muitas vezes, por serem oriundos de famílias ouvintes e não usuários de Libras, chegam à escola sem o domínio da Libras e com muita dificuldade de apreensão dos conteúdos de Língua Portuguesa. Essa realidade, normalmente, leva o professor a investir muito mais tempo do que o previsto para abordar determinados tipos de conteúdos e atividades, assim como acessar vários recursos didáticos e pedagógicos, diferentemente, do que aconteceria em uma turma regular, sem a presença de discentes surdos.

Considerando essa realidade, propomos um Plano de Atividades (PA), pensado de maneira que o professor ou proponente das atividades, das redes municipais, estaduais e privadas, possa articular o conteúdo a ser trabalhado com um gênero textual adequado à faixa etária/escolar e com as estratégias de ensino para alcançar o objetivo proposto. A proposta é articular esse plano à Unidade Didática (UD), constituída por um conjunto de atividades estruturadas para o ensino-aprendizagem de determinado conteúdo. Nesse sentido, o PA e a UD diferem de propostas comuns de trabalho em sala de aula, porque a limitação de tempo e as atividades seguem a visão sociointeracionista (VYGOTSKY, 2004) da linguagem, ou seja, concebem o indivíduo como interlocutor atuante no processo de comunicação.

É importante destacarmos que a concepção de ensino abordada neste 
artigo é baseada na visão de que a língua está inserida em contexto de uso e que o ensino de Libras e de LP deve ser ministrado em uma perspectiva dialógica, instrumental e funcional (BRASIL, 2005), o que converge com os pressupostos teórico-metodológicos da Linguística Sistêmico-Funcional LSF (HALLIDAY, 1985, HALLIDAY; MATHIESSEN, 2004; 2014), pois compartilhamos a ideia de que a linguagem atende às necessidades humanas de interação verbal, isto é, ao uso comunicativo (HALLIDAY, 1973). Para a teoria sistêmico-funcional, o texto é a concretização de um propósito comunicativo específico, situado em uma atividade comunicativa humana.

A visão da linguagem proposta pela LSF permite elaborar atividades a partir do conceito de tarefa desenvolvido por Ellis (2003), originalmente, para o ensino de Língua Estrangeira (LE) e de L2 e reformulado por nós para se adequar ao ensino de LP como L2 para surdos, tendo em vista o foco proposto aqui: ensino de leitura e escrita.

Para Christie e Derewianka (1999), o ensino com base na LSF contribui para a melhora da capacidade crítica na interpretação e na reflexão das maneiras como a linguagem constrói significados. Dessa forma, o PA é desenvolvido pelo professor com base nas necessidades dos aprendizes, mas pode ou não ter os resultados esperados. $\mathrm{O}$ foco da tarefa é o significado, isto é, o aluno usa a língua pragmaticamente, desenvolvendo sua proficiência na língua-alvo com atividades comunicativas, com textos autênticos, em situações reais de comunicação, de modo que os "[...] participantes assumem a função de usuários da língua, uma vez que precisam empregar os mesmos processos comunicativos envolvidos nas atividades do mundo real, e, assim, a aprendizagem é incidental" (ELLIS, 2003, p. 3).

Tradicionalmente, observamos que o professor, ao elaborar uma atividade, pode torná-la artificial, se ela não representar uma ação do mundo real, pois, pedagogicamente, o uso da língua nessa atividade pode não refletir uma situação de sua prática comunicativa real. É importante que os aprendizes tenham consciência sobre os objetivos de cada tarefa, de modo a produzirem os resultados, sem que sejam puramente linguísticos e estruturais.

O foco no significado não quer dizer, entretanto, ausência de foco na forma, uma vez que a forma recebe uma atenção periférica, sendo vivenciada de modo natural, a partir da língua em uso, em determinado contexto sociocultural e a partir de gêneros que apresentam características particulares (HALLIDAY, 1994; HALLIDAY; MATHIESSEN, 2004). A tarefa trabalha com processos cognitivos, como: selecionar, classificar, ordenar, 
raciocinar e avaliar informaçóes, o que influencia em sua dificuldade. Além disso, envolve, na LE, quatro habilidades (ler, escrever, ouvir e falar). Considerando-se a L1 do aluno surdo que é, tipicamente, viso-espacial e a Língua Portuguesa, sua L2, trabalhamos com as duas primeiras habilidades: ler e escrever. Dessa maneira, com base nessa concepção, focamos as práticas de ensino-aprendizagem de Língua Portuguesa no significado envolvido em uma prática comunicativa, não-linguística exclusivamente, tendo em vista que os alunos estão inseridos no contexto social e cultural mais profundo da língua (HALLIDAY, 1989; 1994; HALLIDAY; MATTHIESSEN, 2004; 2014).

Sabemos que o ensino baseado na forma, no texto como pretexto para o ensino de metalinguagem náo contribui para o ensino efetivo de uma língua, pois o ensino deve:

[...] ser centrado em torno do texto, desenvolvendo as competências linguísticas, textuais e comunicativas. A escola sempre trabalhou com texto, porém, muitas vezes, restringe seus ensinamentos aos aspectos estruturais e formais. As práticas de leitura precisam ser contextualizadas, fornecendo condiçóes para que o aprendiz surdo compreenda o texto (MORAIS; CRUZ, 2017, p. 5).

Compreendemos o ensino de línguas baseado em tarefas (ELT) como um desdobramento do Communicative Language Teaching (CLT), sendo uma das várias possibilidades de prática da língua em situaçôes comunicativas reais, com textos autênticos, que circulam na sociedade.

O sócio linguista Hymes (1979), ao incorporar a questão social da língua ao conceito de competência, discordando da visão de Chomsky (1965), muito forte na época, contribuiu para a visão de uso da língua, isto é, Hymes, ao acrescentar o aspecto comunicativo ao termo competência, englobou o conhecimento social e cultural da língua e não somente o saber estrutural/gramatical. Dessa maneira, competência linguística passou a ser vista como conhecimento das formas de uma língua que possa ser usada na comunicação em diferentes contextos, dominando, também, as regras específicas (discursivas) da comunidade na qual se insere.

A competência comunicativa envolve três tipos de modalidade: competência gramatical (regras de uso do sistema linguístico), competência sociolinguistica (regras sociolinguísticas que definem a propriedade dos enunciados - forma e significado) e competência estratégica (estratégias verbais e não verbais usadas em situaçóes de quebras de comunicação causadas por 
dificuldades das outras competências, por exemplo).

Assim, nasceu o ensino comunicativo de línguas, que busca o envolvimento dos aprendizes baseado em tarefas com um propósito (purposeful tasks), inseridas em contextos significativos, refletindo e possibilitando a prática da língua tal qual ela é usada no mundo, fora da sala de aula (HEDGE, 2000, p. 71). Esse conceito pode parecer amplo na literatura especializada, porém, neste artigo, entendemos como um desdobramento do ensino comunicativo de línguas, objetivando a promoção de amostras e a exposição de situaçôes de comunicaçáo autênticas, que possuem um objetivo comunicativo com base na troca de informaçáo, que não seja com foco apenas no desempenho linguístico e estrutura da língua, mas no significado e no uso da língua como prática social. A tarefa é "um plano de trabalho que requer que aprendizes processem a língua pragmaticamente, a fim de atingir um resultado que pode ser avaliado em função de o conteúdo proposto ter sido atingido de forma apropriada" (ELLIS, 2003, p. 16). É requerido que os participantes (aprendizes) trabalhem como verdadeiros usuários da língua, devendo usar os mesmos processos comunicativos envolvidos em atividades autênticas.

O foco primário é a produção de significados, porém isso não exclui que seja dada atenção às formas linguísticas, pois elas também são importantes no ensino-aprendizagem de uma língua-alvo. Para Willis (1996, p. 23), as tarefas são "atividades em que a língua-alvo é usada pelo aprendiz com um propósito comunicativo para se obter um resultado". Seus usos no ensino de línguas envolvem três aspectos:

- Significado é mais importante que a forma (meaning-based);

- Objetivo comunicativo deve ser atingido (goal);

- Um resultado deve ser produzido (outcome).

Um exemplo nesses moldes seria o estudo de um anúncio publicitário, em que os alunos são levados a compreender, primeiramente, o sentido do anúncio, as informaçôes implícitas e explícitas, verbais e não verbais, seu objetivo, a estrutura, a composiçấo do texto e o conjunto de informaçôes que compóem o gênero discursivo anúncio publicitário. Ao conhecer, reconhecer e identificar as características desse gênero discursivo, o aluno poderá familiarizar-se com as peculiaridades linguísticas típicas do gênero discursivo, como, por exemplo, a presença de verbos no modo imperativo, a presença de metáfora, de construçóes ambíguas. Dessa forma, os aprendizes são levados a observar, primeiramente, a organização do gênero, e, posteriormente, os aspectos linguísticos. 


\section{Ensino de leitura e escrita (LP como L2 para surdos)}

Em linhas anteriores, abordamos a conquista da comunidade surda com relaçáo à perspectiva de ensino adotada na atualidade e que demonstra ser adequada ao processo de ensino-aprendizagem para surdos. Nesse sentido, reforçamos que resultados promissores nesse processo apontam para a perspectiva bilíngue de ensino de Língua Portuguesa como L2, a partir de estratégias e recursos visuais e verbais condizentes com a realidade do aluno surdo e com sua cultura e conhecimento prévio.

Compartilhamos com pesquisadores que defendem esse método de ensino, como Fernandes (2003), Pereira (2003; 2014) e Lodi (2013), ao defenderem o ensino de Língua Portuguesa para surdos a partir de algumas consideraçôes, dentre elas: considerar que a falta ou a perda da audição não implicam dificuldades de aprendizagem, e assumir que a responsabilidade do ensino é de vários agentes, a começar pelos familiares, que, muitas vezes, são ouvintes e não usuários da Libras. A aquisição linguística da Libras deve ocorrer o mais cedo possível, portanto, é importante que a criança surda seja contemplada com o contato com a Libras e leitura de textos sinalizados e interpretados antes de ser inserida no contexto escolar e, subsequentemente, à sua segunda língua - a LP escrita, de modo que a aprendizagem seja significativa e faça sentido para o sujeito surdo ao longo de sua vida.

No contexto escolar, é importante que os educadores e participantes do processo de ensino-aprendizagem desse aluno estejam atentos à seleção e produçáo de material didático a ser utilizado com esse aprendiz, buscando, sobretudo, que os textos sejam contextualizados e compreendidos, por meio de recursos visuais adequados e de pistas imagéticas que levem o aprendiz a uma leitura autônoma e eficaz.

O uso de recursos visuais sem sentido e a não exploração do conhecimento prévio desse aluno não fazem contribuem para aprendizagem. Dessa forma, é importante que o professor desenvolva nos alunos o interesse e o gosto pela leitura, por meio de rodas de conversa, reflexóes anteriores à leitura do texto, de modo que o aluno esteja engajado no contexto do que vai ser lido (QUADROS; SCHMIEDT, 2006).

Vale ressaltar que, assim como acontece no processo de ensinoaprendizagem da Língua Portuguesa a um estrangeiro, o ensino de uma L2 para o aprendiz surdo também requer metodologias e estratégias específicas 
para esse fim, em que são necessárias algumas percepções e reflexôes, tais como: a seleção de conteúdo, a consideração sobre o nível de aquisição de língua desse aluno e de sua faixa etária, e estratégias adequadas para atingir o objetivo. Considerando-se que o aprendiz surdo desenvolve seu raciocínio, sobretudo, a partir de sua L1 e de meios visuo-espaciais, o desafio é maior, pois esse aluno não tem acesso aos inputs auditivos como ocorre com aprendizes ouvintes. Então, cabe ao professor recorrer a recursos visuais e linguísticos, usando, predominantemente, a língua de sinais como língua de instrução e como L1 desse aprendiz, articulando entre eles práticas interativas e dialógicas.

A leitura é um instrumento poderoso para o ensino, pois contribui para o aprendizado de uma língua de forma rápida e eficiente. Segundo Pereira (2014), é importante que o aluno surdo seja exposto constantemente a textos em Libras e em Língua Portuguesa escrita. Tomamos como base essa premissa e destacamos a necessidade de se ofertar aos alunos um ambiente escolar propício para o desenvolvimento do letramento, a partir de profissionais bilíngues, da Libras em toda a escola, de textos escritos e sinais indicativos de lugares e setores presentes naquele ambiente frequentado pelo aprendiz.

Autores que pesquisam o processo de ensino-aprendizagem da Língua Portuguesa para surdos defendem o uso de estratégias adequadas, levandose em conta as singularidades linguísticas dos surdos (PEREIRA, 2003; QUADROS, 1997; QUADROS; SCHIMIEDT, 2006; FERNANDES, 2006; MORAIS, 2013; MORAIS; CRUZ, 2016). O papel do professor ou do profissional que trabalha com o surdo deve levar o aluno à reflexão sobre os significados e sentidos dos textos que circulam em Libras e em Língua Portuguesa.

Tendo em vista nossa concepção sobre ensino de Língua Portuguesa escrita a alunos surdos, consideramos importante que o processo de ensinoaprendizagem seja baseado em diferentes gêneros discursivos, como um recurso pedagógico poderoso porque permitem aos participantes (professor e alunos) refletirem sobre os discursos inerentes a cada gênero, além de capacitá-los para entender características desses textos.

Para trabalharmos o ensino baseado em gêneros discursivos, tomamos como base a pesquisa de Ramos (2004), que assim destaca: 
trabalham com o foco exclusivamente no texto, propicia ao professor desenvolver um trabalho em que o uso de textos e questôes de conhecimento sistêmico são trabalhados não mais de forma estanque, mas observando-se suas condiçôes e situação de produção (RAMOS, 2004, p. 116).

Ramos (2004), em suas pesquisas sobre o ensino de línguas para fins específicos, destaca a importância do ensino baseado em gênero discursivo, sendo, em sua visão, o ponto de partida para o desenvolvimento de habilidades de leitura e escrita. Para isso, a pesquisadora divide as etapas de ensino em três fases - Apresentação, Detalhamento e Aplicação do gênero. Embora sua proposta seja voltada para o ensino de línguas estrangeiras e não especificamente ao aprendiz surdo, tem sido utilizada com sucesso por nós na elaboração de materiais didáticos para aprendizes surdos. Cruz (2018), ao abordar o ensino de resenhas acadêmicas para graduandos surdos, sintetiza as fases proposta por Ramos (2004), como apresentado abaixo:

\begin{tabular}{|c|c|c|}
\hline Apresentação & Detalhamento & Aplicação \\
\hline $\begin{array}{l}\text { Acesso às informaçóes gerais } \\
\text { sobre o gênero, como por } \\
\text { exemplo, onde normalmente } \\
\text { ele circula, o objetivo ou } \\
\text { propósito, os participantes } \\
\text { desse evento comunicativo e } \\
\text { suas relaçóes, e os contextos } \\
\text { onde o gênero é produzido e } \\
\text { por que é produzido. }\end{array}$ & $\begin{array}{l}\text { Identificação dos aspectos } \\
\text { gerais e específicos do } \\
\text { gênero, tendo como } \\
\text { base a compreensão e } \\
\text { produção geral e detalhada, } \\
\text { as questôes relativas a } \\
\text { aspectos léxico-gramaticais } \\
\text { particulares do gênero, por } \\
\text { exemplo: tempo e modo } \\
\text { dos verbos, palavras mais } \\
\text { comuns, a estrutura do } \\
\text { gênero e seus significados. }\end{array}$ & $\begin{array}{l}\text { Materialização do gênero. } \\
\text { A partir da assimilaçáo das } \\
\text { características do gênero, } \\
\text { por meio de retomada } \\
\text { da ideia e do conceito } \\
\text { como um todo, o aluno se } \\
\text { apropria do conceito e tem } \\
\text { condiçóes de produzi-lo } \\
\text { efetivamente. }\end{array}$ \\
\hline
\end{tabular}

Quadro 1: Síntese das fases de ensino de gêneros discursivos.

Fonte: Ramos (2004).

Tomando como partida as questóes apresentadas até o momento sobre ensino baseado em tarefas e as consideraçóes acerca do ensino de Língua Portuguesa escrita, apresentaremos a seguir a descriçáo do Plano de Atividades, visando subsidiar o trabalho do professor em termos metodológicos, organizacionais e estratégicos. 


\section{O Plano de Atividades}

Como já mencionado na Introdução deste artigo, nosso objetivo é apresentar duas ferramentas de trabalho: o PA e uma UD - que foram elaborados a partir das concepçóes teórico-metodológicas discutidas neste artigo. Consideramos que o PA consiste no ponto de partida para a elaboração de uma UD, valendo-se de um gênero discursivo que seja suficiente e adequado para abordar os conteúdos propostos no objetivo do professor.

Nosso foco de trabalho é o aluno surdo e a concepção de língua é desenvolvida a partir dos pressupostos sistêmico-funcionais (HALLIDAY, 1994; HALLIDAY; MATTHIESSEN, 2004; 2014), em que o uso da língua é um sistema de escolhas e está sempre inserido em um contexto de cultura (mais amplo) e de situação (mais específico, em nível léxico-gramatical). Assim sendo, partimos de determinado gênero discursivo para abordar os conteúdos necessários para a aprendizagem do aluno surdo, seja em contexto bilíngue ou em contexto regular/inclusivo.

O PA, apresentado e descrito a seguir, é um planejamento de grande valia, sendo fundamental, contribuindo para o trabalho do professor na elaboração e prática em uma sequência didática, de maneira coerente com os objetivos propostos: 
PLANO DE ATIVIDADES

\begin{tabular}{|l|l|}
\hline PROFESSOR(A) & DURAÇAO DA AULA \\
\hline
\end{tabular}

1. Tema:

Qual é o assunto abordado nessa unidade didática?

\begin{tabular}{|l|}
\hline 2. Público-alvo: \\
Qual é a série ou idade do(s) aluno(s) que farão a Unidade Didática? \\
\hline 3. Objetivo(s): Ao final da aula, o aluno deverá ser capaz de: \\
1. Identificar.... EXEMPLOS \\
2. Reconhecer... Elaborar... \\
3. EX
\end{tabular}

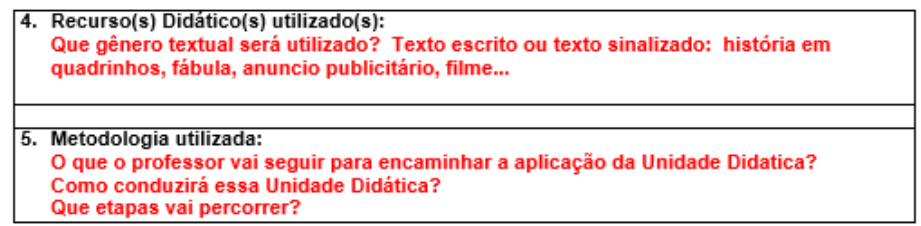

6. Atividade(s) proposta(s):
Que atividades serão desenvolvidas? Pré leitura + leitura + atividades pós leitura

Questões/ Perguntas da Unidade Didática

7. Avaliação:
Como o aluno será avaliado após a realização da Unidade Didática?

Figura 1 - Proposta do plano de atividades

Fonte: Elaborado pelas autoras deste artigo.

A seguir, descrevemos as partes do Plano de Atividades

1. Identificaçáo e duraçáo da atividade - o professor pode elaborar o plano e executar ou elaborar para outro professor aplicar. Por isso, a identificação (nome do professor) é importante. A duração da atividade consiste em uma previsão para o início - meio - fim do planejamento. Vale ressaltar que náo se trata de um plano de aula, por isso, essa duraçáo pode levar 1 aula, 1 bimestre, 1 semestre...

2. Tema - o proponente do planejamento apresenta o(s) assunto(s) a $\operatorname{ser}(\mathrm{em})$ abordado(s).

3. Gênero discursivo - gênero discursivo que servirá de base para a 
abordagem dos conteúdos previstos no planejamento.

4. Público-alvo - indicação da série, idade ou nível escolar em que vai ser aplicado o conteúdo.

5. Objetivo(s) - apresentação das competências ou atividades que o aluno deverá ser capaz de executar ao final do trabalho. Importante ter em mente que objetivo é iniciado por um verbo. Exemplo: ao final da Unidade Didática, o aluno deverá ser capaz de: Identificar....; Reconhecer...; Elaborar...; Compreender...; Produzir...

6. Recurso(s) Didático(s) utilizado(s) - apresentação dos recursos necessários para implementar as atividades. Exemplo: vídeo em Libras com legenda, livro impresso, cartazes com imagens, projetor de slides, quadro, figuras...

7. Procedimentos utilizados - descrição das etapas de ensino, ou seja, os passos que o professor vai seguir para encaminhar a aplicação da atividade. Nessa fase de apresentaçáo das etapas, o professor deve estar consciente da importância do desenvolvimento de tarefas com base em Ellis (2003) e em Ramos (2004) e na proposta sociointeracionista de ensino, além da concepção de ensino da língua, baseado no seu uso e na sua prática e não exclusivamente na gramática tradicional.

Portanto, deve-se pensar em questóes que explorem:

a) O conhecimento prévio dos alunos antes de ler o texto, a PRÉLEITURA: perguntas e sondagem antes da leitura do texto principal. Nas atividades de pré-leitura, o professor estará trabalhando a primeira fase proposta por Ramos (2004) - Apresentação do gênero discursivo. Então, serão apresentadas situaçóes, textos ou conversas de modo que o aluno comece a ter noção do que será trabalhado no decorrer das atividades.

b) LEITURA: compreensão textual, buscando entender e explicar significados explícitos e implícitos, metáforas, informação verbal e não verbal e questóes léxico-gramaticais - uso da língua, registro formal/não formal/, emprego das palavras em diferentes contextos de uso, sintaxe. As atividades desenvolvidas na leitura correspondem à segunda fase proposta por Ramos (2004) - Detalhamento do gênero discursivo, em que são exploradas as partes mais específicas do texto e do gênero.

c) PRODUÇÃO TEXTUAL: após a realizaçáo das etapas anteriores, o professor terá trabalhado o gênero como um todo, em termos de 
reconhecimento, identificação, questôes linguísticas e gramaticais, de forma que o aluno tenha apreendido informaçóes suficientes para produzir textos em Libras e em LP escrita. Então, ele poderá elaborar textos que demonstrem a consolidaçáo da aprendizagem, ou seja, poderá, por exemplo, elaborar o gênero discursivo abordado. A terceira fase apresentada por Ramos (2004) - Aplicação do gênero discursivo, que consiste na produção do gênero estudado de forma consciente do que se trata, de sua funçáo social e de sua estrutura e composição léxico-gramatical.

8. Atividade(s) proposta(s) - este item é a própria Unidade Didática, pois vai reunir as tarefas de forma organizada e coerente, seguindo as informaçóes apresentadas no item 7 (procedimentos). Reiterando, a UD vai contemplar a proposta de Ramos (2004):

a) Pré-leitura - fase de Apresentação;

b) Leitura - fase de Detalhamento (continuação da fase anterior Apresentação);

c) Produção - fase de Aplicação (consolidaçáo das fases anteriores Apresentaçáo e Detalhamento).

9. Avaliaçáo - essa parte do planejamento deve ser muito bem executada pelo professor, uma vez que avaliar a produção do aluno surdo significa estar atento a todos os avanços e entender que a produção escrita desse aluno é uma produçáo em L2. Dessa forma, cabe ao docente pensar no processo de evolução e de desenvolvimento do aluno. A avaliaçáo pode ser vista dentro de um processo contínuo, em atividades interativas, em grupo, individualizadas, produçáo em L1 e em L2, etc.

Questóes importantes a serem consideradas pelo professor: Que tipo de avaliação será realizado - Avaliação formativa, Avaliação somativa, Avaliação diagnóstica? Além disso, quais serão os instrumentos para a avaliação: Processo contínuo? Prova isolada? Participação nas atividades? Produção em Libras, Produçáa em LP escrita? E o professor - em que momento ocorre sua autoavaliação?

10. Observaçóes importantes - este espaço deve ser utilizado pelo professor para incluir esclarecimentos, hipóteses, preocupaçóes ou observaçóes sobre a proposta de ensino e sobre a flexibilização da UD, dependendo da característica ou especificidade dos aprendizes, assim como do contexto em que a UD vai ser implementada - bilíngue ou regular/ 
inclusivo.

Para ilustrar nossa proposta, a seguir, apresentamos um exemplo de plano e uma versão compactada de UD sobre o tema profissóes para ser utilizada no primeiro ciclo do Ensino Fundamental. Vale ressaltar que os sinais foram extraídos do site Google imagens e que o objetivo é tornar o aluno um leitor independente, por isso, alguns comandos de atividades trazem os sinais referentes aos pronomes interrogativos e as palavras equivalentes aos sinais estão em negrito na questão. Dessa forma, o aluno surdo vai se tornando habituado aos tipos de perguntas, desenvolvendo as habilidades de compreensão da pergunta e de atendimento ao comando.

PLANO DE ATIVIDADES

\begin{tabular}{|c|c|}
\hline PROFESSOR(A) & $\begin{array}{l}\text { DURAÇAO DA ATIVIDADE } \\
16 \text { horas }\end{array}$ \\
\hline \multicolumn{2}{|l|}{ 1. Tema: Profissőes } \\
\hline \multicolumn{2}{|c|}{ 2. Gênero textual: Tirinha sobre profissões - Competição de profissões } \\
\hline \multicolumn{2}{|c|}{ 1. Público-alvo: $3^{\circ}$ ano Ensino Fundamental - alunos surdos (9 a 13 anos aprox..) } \\
\hline \multicolumn{2}{|c|}{$\begin{array}{l}\text { 2. Objetivo(s): Ao final da atividade, o aluno deverá ser capaz de: } \\
\text { 1. Conhecer os diferentes tipos de profissão; } \\
\text { 2. Identificar os sinais e as palavras escritas referentes às profissões; } \\
\text { 3. Compreender as atividades relacionadas às profissões estudadas; } \\
\text { 4. Pesquisar sobre outras profissóes além das estudadas em sala; } \\
\text { 5. Produzir texto sobre profissöes. }\end{array}$} \\
\hline
\end{tabular}

\section{Recurso(s) Didático(s) utilizado(s):}

Perguntas provocativas; Tirinha; vídeo em Libras sobre Profissões; projetor de slides, quadro, figuras e imagens...

4. Metodologia utilizada:

Todas as atividades serão feitas de forma interativa, em Libras primeiramente, para desenvolver habilidades de leitura e produção de textos em Libras e em LP.

5. Atividade(s) proposta(s): seguir Ramos (2004)

Pré-leitura - fase de Apresentação - perguntas introdutórias e provocativas para saber o que o aluno sabe sobre profissäo

Leitura - fase de Detalhamento (e Apresentação) - leitura da tirinha e atividades de compreensão do texto e escrita das profissões

Produção - fase de Aplicação (Apresentação e Detalhamento) - pesquisa sobreoutras profissões e producão escrita sobre uma profissão.

\section{Avaliaçăo:}

O aluno será avaliado durante todo o processo, por meio de atividades em sala, de suas expressões em Libras e em LP. O processo avaliativo é contínuo, destacando a participação nas atividades e suas produções em Libras e em LP escrita.

\section{Observaçỏes importantes}

Planejamento visando o trabalho em turma bilíngue (somente surdos), com professor bilíngue, ou regular (surdos e ouvintes), com professor bilingue ou presença de intérprete

- Esse plano pode ser realizado contemplando uma atividade específica ou uma Unidade Didática mais ampla. Por isso, a quantidade de aulas pode variar.

Figura 2 - Exemplo de plano de atividades. 
Fonte: Elaborado pelas autoras deste artigo.

Abaixo, segue exemplo de unidade didática, elaborada com base no plano acima:

\section{I - Pré-leitura}

(Esta etapa deverá ser feita em Libras, explorando a compreensão do aluno)

O que vocês querem fazer quando crescerem?

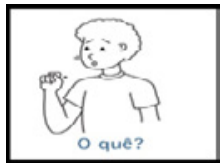

2. (dependendo da resposta) E o que faz um (NOME DA PROFISSÁO)?

3. Onde trabalha o (NOME DA PROFISSÃO)?

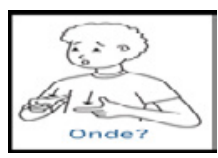

4. O que estuda para ser um (NOME DA PROFISSÃO)?

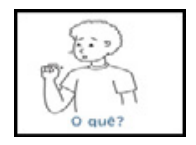

II - Leitura

(Assim como na etapa anterior, a mediação é feita por meio da Libras. A proposta da pré-leitura é a compreensão das semioses que compóem os quadrinhos. Os alunos leem as imagens e expressam o entendimento do conjunto em Libras. Em seguida, nesta etapa, leem o português escrito e discutem em Libras. Dessa maneira, a leitura feita do material multimodal é em Libras).

Vamos ver a tirinha a seguir com muita atenção e depois responder as perguntas. 


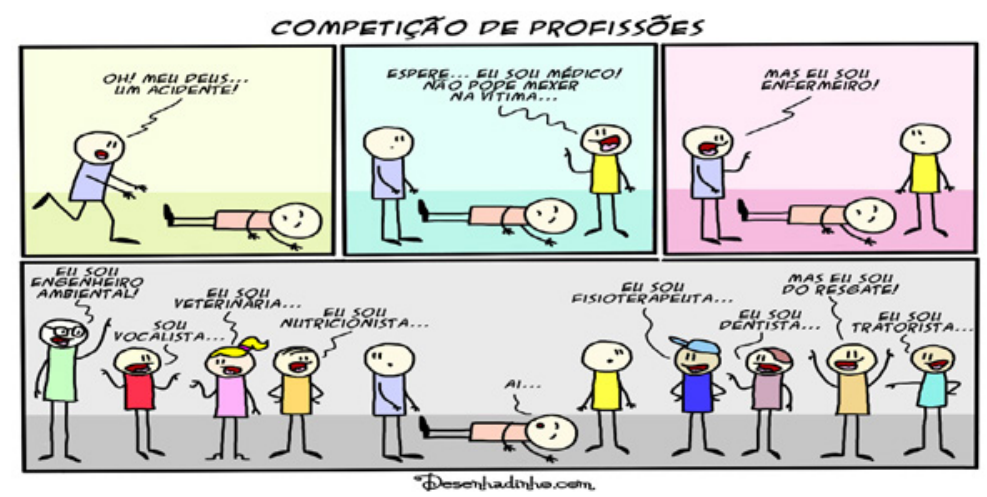

Fonte: Desenhadinho.com

1. Qual é o título da tirinha?

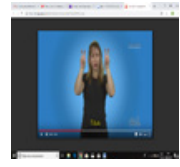

2. Qual é o significado do título "COMPETIÇÃO DE PROFISSÓES"?

3. O que acontece na tirinha?

4. Que palavras da estória você conhece? Explique aos colegas.

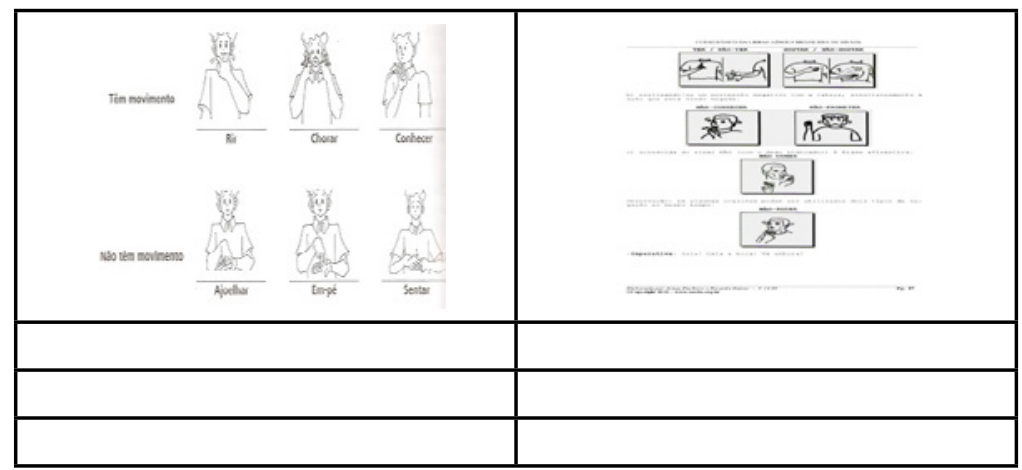

5. A pessoa que está deitada no chão é:

( ) doente ( ) atendente ( ) atleta ( ) estudioso ( ) preguiçoso 6. A pessoa que está no chão foi atendida? 


\section{( ) SIM ( ) NÃO}

7. Explique sua resposta.

8. $\mathrm{Na}$ sua opinião, entre todas as profissóes que aparecem na tirinha, qual ou quais podem socorrer a pessoa que está deitada no chão?

9. Explique sua resposta.

10. Vamos assistir a um vídeo em Libras sobre profissôes? Prestem atenção e depois conversem com seus colegas sobre o que você aprendeu.

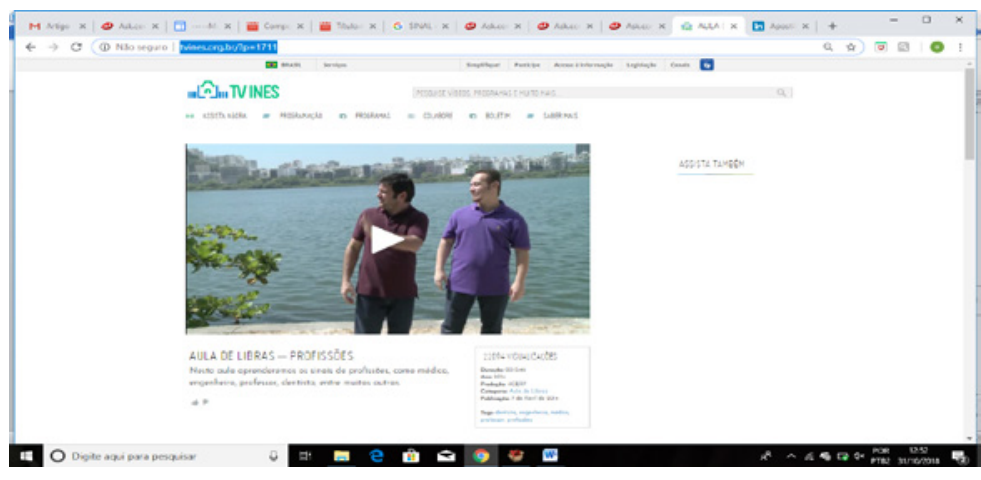

Link: http://tvines.org.br/?p=1711

11. Coloque no quadro o número que corresponde a cada profissão abaixo. Explique sua resposta.

1

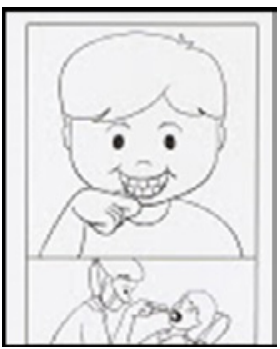

2

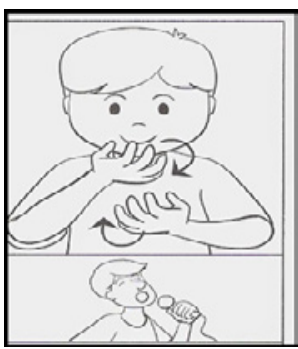

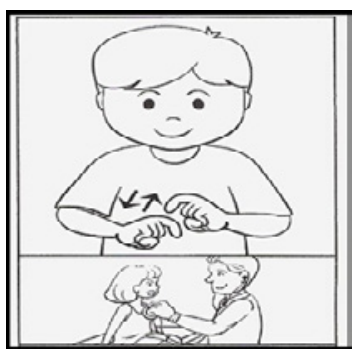


4

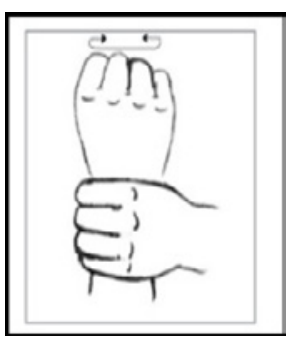

5

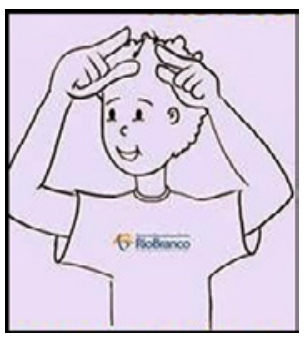

6

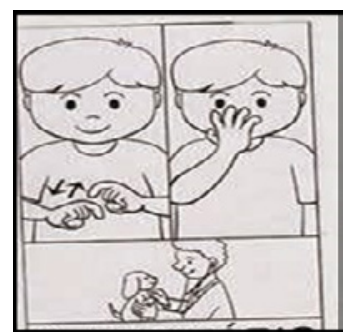

\begin{tabular}{|l|l|l|}
\hline Enfermeiro & Fisioterapeuta & Vocalista \\
\hline Veterinário & Dentista & Médico \\
\hline
\end{tabular}

12. Então, o que faz cada profissional?

\begin{tabular}{|l|}
\hline \\
\hline \\
\hline \\
\hline \\
\hline
\end{tabular}

III - Pós-leitura e produção escrita

13. E agora, vamos escrever profissão referente ao desenho.
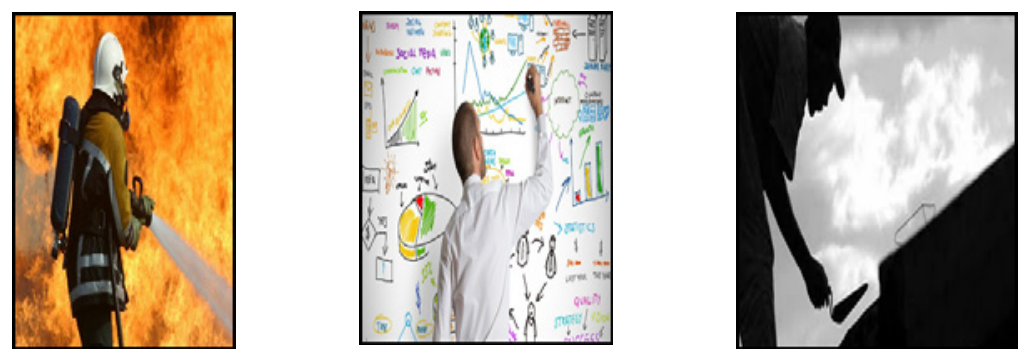

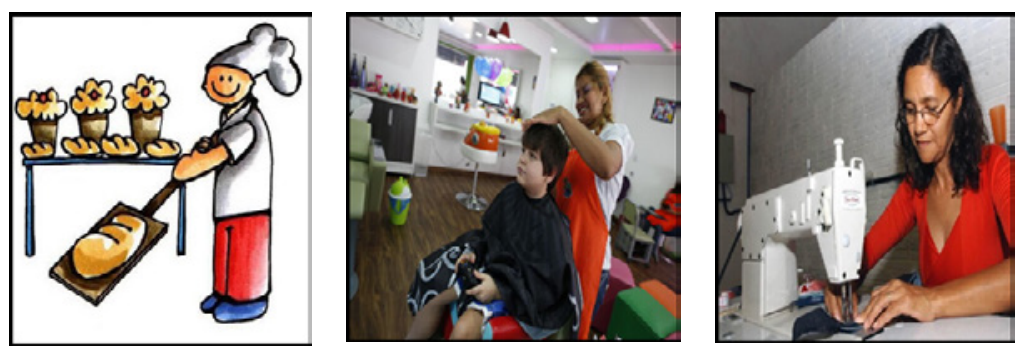

14. Agora, você vai pesquisar em casa outras profissóes e trazer gravuras para mostrar aos seus colegas (aqui será uma oportunidade para o aluno pesquisar, pedir a participaçáo de outra pessoa em casa e compartilhar o conhecimento).

15. Escreva sobre uma profissão. Não se esqueça de explicar:

O QUE FAZ?

ONDE TRABALHA?

COM QUEM COSTUMA TRABALHAR?

O QUE ESTUDA PARA EXERCER ESSA PROFISSÃO?

\section{Consideraçóes Finais}

Nosso objetivo, neste artigo, consistiu em oferecer a profissionais que atuam na educação de surdos um material que possa contribuir para a prática em sala de aula, baseadas em nossas experiências de ensino a partir de uma perspectiva bilíngue, em que as duas línguas (Libras e LP escrita) convivem de forma instrumental, funcional e dialógica, conforme previsto no Decreto no 5.626/2005 e nas concepçóes teóricas da Linguística Sistêmico-Funcional, sobre as quais nos debruçamos em nosso grupo de pesquisa. Nesse sentido, buscamos inspiraçóes em outras concepçóes sobre ensino, de forma a contribuir para uma sistematização sobre o ensino de línguas baseado em tarefas com enfoque comunicativo, priorizando o contato dos alunos com situaçóes reais de comunicação e envolvendo o uso de gêneros textuais que circulam em na sociedade. Para a sistematizaçáo e organizaçáo das atividades do professor, apresentamos um instrumento de 
trabalho que visa auxiliar professores em formação e também professores que atuam com aprendizes surdos na Educação Básica, promovendo a elaboraçáo de tarefas comunicativas e o ensino efetivo da Língua Portuguesa como Segunda Língua para Surdos.

$\mathrm{O}$ instrumento de trabalho proposto neste artigo, portanto, visa auxiliar o professor, em sua resistência do fazer pedagógico, a refletir e elaborar atividades estruturadas para o ensino-aprendizagem de determinado conteúdo, levando em conta as necessidades e os anseios dos aprendizes. É importante garantir o foco na prática social da linguagem, isto é, no significado e no uso da língua em situaçōes reais de comunicação, promovendo o incentivo à leitura mais autônoma e ao amplo desenvolvimento da competência comunicativa, possibilitado pelo uso de textos autênticos que representam propósitos comunicativos específicos, fundamentais para a composição das Unidades Didáticas.

Acreditamos que o PA e a UD podem ser utilizados para a confecção do próprio material didático, em contextos escolares em que não há um livro didático adotado, além de poderem ser utilizados para elaboração de materiais complementares, com temáticas de interesse do aluno.

\section{Referências}

BRASIL. Lei no 10.436, de 24 de abril de 2002. Dispóe sobre a Língua Brasileira de Sinais - LIBRAS e dá outras providências. Disponível em: <http:www.planalto.gov.br>. Acesso em: 07 jan. 2015.

BRASIL. Decreto No 5.626, de 22 de dezembro de 2005, que regulamenta a Lei $\mathrm{n}^{\circ} 10.436$, de 24 de abril de 2002, que dispóe sobre a Língua Brasileira de Sinais - LIBRAS, e o art. 18 da Lei no 10.098, de 19 de dezembro de 2000. Disponível em: <http:www.planalto.gov.br>. Acesso em: 07 jan. 2015.

BRASIL. Lei no 12.319, de $1^{\text {o }}$ de setembro de 2010. Regulamenta a profissão de Tradutor e Intérprete da Língua Brasileira de Sinais - LIBRAS. Brasília, 2010. Disponível em: <http:www.planalto.gov.br>. Acesso em: 07 jan. 2015.

BRASIL, 2015, Lei n. 13.146, de 6 de jul. de 2015. Lei Brasileira de Inclusão da Pessoa com Deficiência. Disponível.em: http://www.planalto.gov. br/ccivil 03/ Ato2015-2018/2015/Lei/L13146.htm. Acesso em: 24 Abril 2017. 
CHOMSKY, N. Aspectos da Teoria da Sintaxe. Coimbra: Armênio Amado. 1965.

CHRISTIE, F; DEREWIANKA, B. School Discourse. London: Continuum, 1999.

CRUZ, O. M. S. Avaliação e Avaliatividade em discursos de alunos surdos à luz da LSF. DELTA: Documentação e Estudos em Linguística Teórica e Aplicada, [S.1.], v. 34, n. 1, jul. 2018.

DECLARAÇÃO DE SALAMANCA: Sobre Princípios, Políticas e Práticas na Área das Necessidades Educativas Especiais. Salamanca-Espanha, 1994.

ELLIOT, J. La investigación-acción en educación. Tradução de Pablo Manzano. 3. ed. Madrid: Morata, 1997.

ELLIS, R. Task-based learning and teaching. Oxford: Oxford University Press, 2003.

FERNANDES, S. Educaçáo bilíngue para surdos: identidades, diferenças, contradiçôes e mistérios. Tese (Doutorado em Letras) - Unidade ou Instituto, Universidade Federal do Paraná, Curitiba, 2002.

FERNANDES, S. Práticas de letramento na educaçáo bilíngue para surdos. Curitiba: SEED/SUED/DEE, 2006.

HALLIDAY, M. A. K.; MATTHIESSEN, C. M.I.M. An introduction to Functional Grammar. Londres: Edward Arnold. Third Edition, 2004.

HALLIDAY, M. A. K.; MATTHIESSEN, C. M.I.M. An introduction to Functional Grammar. Londres: Edward Arnold. Third Edition, 2014.

HEDGE, T. Teaching and learning in the language classroom. Oxford: Oxford University Press, 2000.

HYMES, D. On Communicative Competence. Linguistic Background. University of Pennsylvania Press. s/a 1979.

LODI, A. C. B. Educação bilíngue para surdos e inclusão segundo a Política Nacional de Educaçáo Especial e o Decreto no 5.626/05. Educaçáo e Pesquisa, Cidade, v. 39, n. 1, p. 49-63, jan./mar. 2013.

MORAIS, F. B. C. O gênero resumo: compreensão escrita em contexto de sala de aula bilíngue. Arqueiro, Rio de Janeiro, v 25, p. 28-38, 2013.

MORAIS, F. B. C.; CRUZ, O.M.S. O gênero história em quadrinhos na sala de aula de LP como L2. Domínios da Linguagem, Uberlândia-MG, v. 11, n. 1, 2016. 
. Ensino de Língua Portuguesa como L2 para surdos: proposta de unidade didática sob a perspectiva sistêmico-funcional. In: ROVATTA, L; NAUJORKS, J. (Org.). Linguística Sistêmico-Funcional - Interlocuçôes na Formação Docente e no Ensino. Porto Alegre, RS: UFRGS, 2017.

Leitura, escrita e surdez. São Paulo: Secretaria de Educação do Estado de São Paulo, 2003.

. O ensino de português como segunda língua para surdos: princípios teóricos e metodológicos. Educar em Revista, Curitiba, Edição Especial n. 2, p. 143-157, 2014.

QUADROS, R. M. Educaçáo de surdos: a aquisiçâo da linguagem. Porto Alegre: Artmed, 1997.

QUADROS, R. M., SCHMIEDT, M. L. P. Ideias para ensinar português para alunos surdos. Brasília: MEC, SEESP, 2006.

RAMOS, R. C. G. Gêneros Textuais: Uma Proposta de Aplicação em Cursos de Inglês para Fins Específicos. The Especialist, São Paulo-SP, v. 25, n. 2, 2004.

THIOLLENT, M. Metodologia da pesquisa-açáo. 11. ed. São Paulo, SP: Cortez, 2002.

TRIPP, D. Pesquisa-ação: uma introdução metodológica. Educação \& Pesquisa, São Paulo, v. 31, n. 3, p. 443-466, set./dez. 2005.

VIGOTSKY, L. S. Teoria e método em psicologia. São Paulo, SP: Martins Fontes, 2004.

WILLIS, J. A framework for task-based learning. Harlow: Longman, 1996. 